\title{
Analisis Peningkatan Daya Saing Produk Melalui Manajemen Sumber Daya Manusia (Studi pada BPJS Kesehatan Cabang Bone)
}

\author{
Muhammad Ikram \\ Institut Agama Islam Negeri (IAIN BONE) \\ Muhammadikram@gmail.com \\ Rusdiawan \\ Sekolah Tinggi Agama Islam (STAI) Al -Furqan Makassar \\ Rusdiawan@gmail.com
}

\begin{abstract}
This study aims to find out (1) how is the position of BPJS Health Bone Branch product competitiveness from five Branch Offices in South Sulawesi over the past three years? (2) how is the role of Human Resources BPJS Branch Bone Management in an effort to improve the position of product competitiveness?. Based on the objectives of the above research, the type of research used is field research using a qualitative approach. This study uses the method of observation, interviews, and documentation in collecting the required data. The collected data is then processed using the Descriptive Analysis analysis method. The results of the study show the position of Branch Bone BPJS Health product competitiveness from 2014-2016 has never occupied the first position of the five Branch Offices in South Sulawesi, but has increased in 2015 from third to second and in 2016 still in second place. And the role of Human Resource BPJS Kesehatan Bone management in an effort to support increased product competitiveness is divided into three roles: (1) Role of Administration, namely by implementing competencybased performance management system applications in every employee activity, (2) Operational Role, namely many are oriented towards training and development as well as employee competency systems which can be seen from a number of training activities that are always carried out by BPJS Health which leads to improving employee competencies, and (3) Strategic Roles, namely implementing talent management that aims to get employees with high employment .
\end{abstract}

Keywords: Competitiveness, Role of Human Resource Management, Bone Branch Health BPJS

\begin{abstract}
Abstrak
Penelitian ini bertujuan untuk mengetahui (1) bagaimana posisi daya saing produk BPJS Kesehatan Cabang Bone dari lima Kantor Cabang di Sulawesi Selatan selama tiga tahun terakhir ?. (2) bagaimana peran Manajemen sumber daya manusia BPJS Kesehatan Cabang Bone dalam upaya meningkatkan posisi daya saing produk ?.Berdasarkan
\end{abstract}

Jurnal Ilmiah Al Tsarwah

Program Magister Program Studi Ekonomi Syariah

Institut Agama Islam Negeri (IAIN) Bone 
tujuan penelitian di atas, maka jenis penelitian yang digunakan adalah penelitian lapangan dengan menggunakan pendekatan kualitatif. Penelitian ini menggunakan metode observasi, wawancara, dan dokumentasi dalam mengumpulkan data yang diperlukan. Data yang telah terkumpul kemudian diolah dengan menggunakan metode analisis Descriptive Analysis. Hasil penelitian menunjukkan posisi daya saing produk BPJS Kesehatan Cabang Bone dari tahun 2014-2016 tidak pernah menempati posisi pertama dari lima Kantor Cabang yang ada di Sulawesi Selatan, Namun mengalami peningkatan pada tahun 2015 dari posisi ketiga ke posisi kedua dan pada tahun 2016 masih berada pada posisi kedua. Dan peran manajemen sumber daya manusia BPJS Kesehatan Cabang Bone dalam upaya mendukung peningkatan daya saing produk terbagi atas tiga peran yakni : (1) Peran Administrasi, yaitu dengan menerapkan aplikasi sistem manajemen kinerja berbasis kompetensi dalam setiap aktivitas pegawai, (2) Peran Operasional, yaitu banyak berorientasi pada pelatihan dan pengembangan serta sistem kompetensi pegawai yang terlihat dari beberapa kegiatan diklat yang senantiasa dilakukan oleh BPJS Kesehatan yang mengarah pada peningkatan kompetensi pegawai., dan (3) Peran Strategis, yaitu menerapkan manajemen talenta yang bertujuan untuk mendapatkan pegawai dengan indeks kerja tinggi.

Kata Kunci : Daya Saing, Peran Manajemen Sumber Daya Manusia, BPJS Kesehatan Cabang Bone

\section{PENDAHULUAN}

Dewasa ini persaingan dalam dunia usaha semakin ketat. Daya saing merupakan salah satu kriteria yang menentukan keberhasilan suatu usaha. Daya saing merupakan suatu penopang eksistensi suatu usaha untuk tetap berdiri secara berkelanjutan di tengah persaingan dengan usaha lainnya yang telah lama berdiri maupun pesaing-pesaing baru yang muncul. Daya saing mengindikasikan bagaimana suatu badan usaha atau organisasi bisnis mampu berkompetisi dengan usaha lain yang sejenis ataupun non sejenis dengan memanfaatkan keunggulan-keunggulan yang dimilikinya untuk menarik perhatian konsumen ${ }^{1}$. Dalam suatu perusahaan, sumber daya manusia merupakan faktor yang sangat penting. Suatu perusahaan sudah tentu mempunyai visi dan misi untuk mencapai tujuan bersama, namun untuk mencapai tujuan yang telah ditentukan dibutuhkan manajemen yang baik dan benar.

\footnotetext{
${ }^{1}$ Yudhi Syafitri, "Analisis SWOT dalam Upaya Meningkatkan Keunggulan bersaing pada Salon Cleopatra" Penelitian (Medan, Universitas Sumatera Utara, 2010), h. 1.
} 
Manajemen sumber daya manusia selama ini lebih banyak berperan dalam hal-hal yang menyangkut penyelenggaraan hubungan industrial di perusahaan, seperti pembuatan peraturan perusahaan atau kesepakatan kerja bersama, menjalin kerjasama dengan departemen tenaga kerja, menyelesaikan perselisihan antara perusahaan dengan serikat pekerja atau karyawan. Yang lebih menyedihkan lagi bila manajemen sumber daya manusia hanya dianggap penting saat perusahaan ingin melakukan pengurangan jumlah karyawan. Selain itu, manajemen sumber daya manusia juga seringkali dipersepsikan perannya tidak lebih sebagai pelaksana administrasi personalia, yaitu yang mengurus masalah pembayaran gaji karyawan, mengurus cuti karyawan, penggantian biaya kesehatan dan sebagainya.

Badan Pusat Jaminan Sosial (BPJS) Kesehatan merupakan Badan Usaha Milik Negara yang ditugaskan khusus oleh pemerintah untuk menyelenggarakan jaminan kesehatan bagi seluruh rakyat Indonesia, terutama untuk Pegawai Negeri Sipil, pensiunan Pegawai Negeri Sipil dan TNI/Polri, veteran, perintis kemerdekaan beserta keluarganya dan badan usaha lainnya maupun rakyat biasa.

BPJS Kesehatan Cabang Bone merupakan salah satu dari enam Kantor Cabang yang ada di Sulawesi Selatan. Adapun produk untuk kepesertaan BPJS Kesehatan adalah Jaminan Kesehatan Nasional atau biasa disingkat JKN-KIS. Pencapaian jumlah kepesertaan JKN-KIS BPJS Kesehatan Cabang Bone pada tahun 2016 adalah sejumlah 1.182.466 jiwa. ${ }^{2}$

BPJS Kesehatan Cabang Bone menaungi wilayah kerja Kabupaten Bone, Soppeng, Wajo, dan Sinjai. Sehubungan dengan visi BPJS Kesehatan yaitu terwujudnya Jaminan Kesehatan yang berkualitas dan berkesinambungan bagi seluruh Penduduk Indonesia pada tahun 2019 yang berkeadilan melalui BPJS Kesehatan yang handal, unggul dan terpercaya, maka BPJS Kesehatan Cabang Bone harus memenuhi target cakupan kepesertaan untuk seluruh penduduk dari empat Kabupaten tersebut.

\footnotetext{
${ }^{2}$ Hasil Dokumentasi data Jumlah Peserta JKN-KIS KC Watampone di BPJS Kesehatan Kantor Divisi Regional IX Makassar.
} 
Visi tersebut juga menjadi titik tolak dari budaya kerja BPJS Kesehatan dan menjadi tuntutan bagi semua aspek manajemen perusahaan untuk memiliki kinerja yang baik agar visi tersebut dapat tercapai. Khusus pada aspek manajemen sumber daya manusia dituntut untuk menghasilkan kinerja karyawan yang maksimal dan mampu meningkatkan daya saing produk perusahaan melalui pelaksanaan fungsi-fungsi manajemen sumber daya manusia. Oleh karena itu, perlu ada upaya-upaya sistematis dan strategis dalam mengelola sumber daya manusia di perusahaan. ${ }^{3}$ Berdasarkan uraian latar belakang di atas, maka rumusan masalah dari penelitian ini adalah Bagaimana peningkatan daya saing produk BPJS Kesehatan Cabang Bone dari lima Kantor Cabang di Sulawesi Selatan selama tiga tahun terakhir dan Bagaimana peran Manajemen Sumber Daya Manusia BPJS Kesehatan Cabang Bone dalam upaya meningkatkan posisi daya saing produk .

\section{METODE}

\section{Jenis Penelitian}

Jenis penelitian yang digunakan adalah penelitian lapangan (field research). Metode ini bermaksud menggambarkan, memaparkan keadaan obyek penelitian pada saat sekarang, yaitu menggambarkan tentang dan posisi daya saing produk peran manajemen sumber daya manusia dalam meningkatkan posisi daya saing produk di BPJS Kesehatan Cabang Bone.

2. Pendekatan Penelitian

Penelitian ini menggunakan pendekatan kualitatif. Pendekatan kualitatif adalah pendekatan penelitian yang relevan untuk memahami fenomena sosial (tindakan manusia). ${ }^{4}$ Dimana data hasil penelitian tidak diolah melalui prosedur

\footnotetext{
${ }^{3}$ Hadari Nawawi, Perencanaan SDM untuk Organisasi Profit Kompetitif (Cet. I; Yogyakarta: Gajah Mada University Press, 2003), h. 38. h. 42 .

${ }^{4}$ Burhan Bungin, Metode Penelitian Kualitatif (Cet. I; Jakarta: PT. Raja Grafindo Persada, 2007),
}

Jurnal Ilmiah Al Tsarwah 
statistik melainkan analisis data dilakukan secara induktif. ${ }^{5}$

Pendekatan kualitatif ini merupakan pendekatan yang memusatkan perhatian pada prinsip-prinsip umum yang mendasari perwujudan sebuah makna dari gejala-gejala sosial masyarakat untuk mendapatkan gambaran umum mengenai kategorisasi tertentu. ${ }^{6}$

\section{Lokasi Penelitian}

Tempat penelitian berlokasi di BPJS Kesehatan Cabang Bone yang terletak di JI. HOS Cokroaminoto No. 34 Watampone, Kab. Bone, Sulawesi Selatan.

\section{Data dan Sumber Data}

Data merupakan bentuk jamak dari kata datum, yang berasal dari bahasa Latin. Data dapat diartikan sebagai fakta-fakta atau bisa dikatakan sebagai serangkaian bukti-bukti, sesuatu yang secara pasti diketahui atau serangkaian informasi yang ada di sekitar kita. ${ }^{7}$

Pengumpulan data dilakukan untuk memperoleh informasi yang dibutuhkan dalam rangka mencapai tujuan penelitian. Dalam penelitian ini, sumber data yang digunakan adalah data primer dan data sekunder. Untuk lebih jelasnya dapat diuraikan sebagai berikut:

a. Data Primer

Data primer merupakan jenis data yang diperoleh dari sumber utama (sumber asli), baik berupa data kualitatif maupun kuantitatif. Sesuai dengan asalnya dari mana data tersebut diperoleh, maka data ini sering pula disebut dengan istilah data mentah ( raw data). ${ }^{8}$ Dalam hal ini, data perimer yaitu data yang diperoleh langsung dari hasil wawancara dengan narasumber atau informan yang dianggap sangat berpotensi dalam memberikan informasi yang

${ }^{5}$ Sugiyono, Metode Penelitian Kuantitatif Kualitatif R\&D (Cet. XVII; Bandung: Alfabeta, 2012), h. 9.

${ }^{6}$ Burhan Bungin, Sosiologi Komunikasi: Teori, Paradigma, dan Diskursus Teknologi Komunikasi di Masyarakat Ed. 1 (Cet. VI; Jakarta: Kencana Prenada Group, 2013), h. 306.

${ }^{7}$ Muhammad Teguh, Metodologi Penelitian Ekonomi: Teori dan Aplikasi Ed. 1(Cet. III; Jakarta: RajaGrafindo Persada, 2005), h. 118.

${ }^{8}$ Muhammad Teguh, Metodologi Penelitian Ekonomi: Teori dan Aplikasi h. 122. 
relevan dan sebenarnya di lapangan dan juga hasil observasi. Adapun yang menjadi informan dalam penelitian ini adalah Manajer sumber daya manusia BPJS Kesehatan Cabang Bone.

b. Data Sekunder

Data sekunder sering juga disebut dengan penelitian meja (desk study). Peneliti tidak perlu mencari data melalui survey, baik lewat kuesioner ataupun lewat wawancara dan sebagainya. Semua data sudah tersedia dimedia cetak atau media elektronik. Media cetak yang dapat dijadikan sumber adalah, laporan penelitian sebelummnya, jurnal- jurnal yang diterbitkan oleh lembaga-lembaga, laporan-laporan prospectus perusahaan (penelitian tentang keuangan perusahaan) dan lain-lain. Sementara itu, media elektronik yang dapat dijadikan sumber adalah internet. Hanya dengan mengunjungi situs- situs tertentu, maka data yang diperlukan dapat diperoleh. ${ }^{9}$

\section{Teknik Pengumpulan Data}

Metode yang digunakan dalam mengumpulkan data-data dalam penelitian ini adalah sebagai berikut:

a. Observasi

Observasi merupakan serangkaian aktivitas yang dilakukan oleh peneliti terhadap suatu proses atau objek dengan maksud untuk memahami pengetahuan dari sebuah fenomena/perilaku berdasarkan pengetahuan dan gagasan yang sudah diketahui sebelumnya. Observasi bisa diartikan sebagai suatu pengamatan yang dilakukan terhadap objek penelitian. ${ }^{10}$

b. Wawancara

Wawancara adalah pengumpulan data yang dilakukan dengan bertanya jawab langsung kepada responden. ${ }^{11}$ Metode ini penulis gunakan untuk memperoleh informasi tentang peran manajemen sumber daya manusiaBPJS

\footnotetext{
${ }^{9}$ Hendri Tanjung dan Abrista Devi, Metodologi Penelitian Ekonomi Islam Ed. 1 (Cet. I: Jakarta; Gramata Publishing, 2013), h. 94-95.

${ }^{10}$ Hendri Tanjung dan Abrista Devi, Metodologi Penelitian Ekonomi Islam h. 93.

${ }^{11}$ Hendri Tanjung dan Abrista Devi, Metodologi Penelitian Ekonomi Islam h. 83.
} 
Kesehatan Cabang Bone dalam upaya meningkatkan posisi daya saing produk.

c. Dokumentasi

Dokumentasi merupakan instrumen yang digunakan untuk mendapatkan data-data primer dengan melalui data-data dari prasasti, naskah-naskah kearsipan (baik dalam bentuk barang cetakan maupun rekaman), artikel, brosur, data gambar/foto/blue print dan lain sebagainya. ${ }^{12}$

Menurut Deddy Mulyana, suatu dokumen dapat mengungkapkan bagaimana subjek mendefinisikan dirinya sendiri, lingkungan, dan situasi yang dihadapinya pada suatu saat, serta bagaimana kaitan antara definisi diri tersebut dalam hubungan dengan orang-orang di sekelilingnya dengan tindakan-tindakannya. ${ }^{13}$

Dokumentasi digunakan untuk mengumpulkan data sekunder yang terdiri dari: data cakupan kepesertaan produk BPJS Kesehatan, buku-buku literatur, buku-buku yang terkait dengan penelitian, dan sebagainya.

6. Teknik Analisis Data

Dalam menganalisis data-data yang telah dikumpulkan maka diperlukan alat analisis. Alat analisis yang digunakan dalam penelitian ini adalah teknik Descriptive Analysis. Burhan Bungin menjelaskan bahwa penelitian sosial menggunakan format deskriptif bertujuan untuk menggambarkan, meringkaskan berbagai kondisi, berbagai situasi atau berbagai fenomena yang timbul dimasyarakat yang menjadi objek penelitian, dan berupaya menarik realitas itu kepermukaan sebagai suatu ciri atau gambaran tentang kondisi, situasi atau fenomena tertentu. ${ }^{14}$

\footnotetext{
${ }^{12}$ Supardi, Metodologi Penelitian Ekonomi \& Bisnis (Cet. I; Yogyakarta: UII Press, 2005), h. 138.

${ }^{13}$ Deddy Mulyana, Metodologi Penelitian Kualitatif: Paradigma Baru IImu Komunikasi dan IImu Sosial Lainnya (Cet. III; Bandung: Remaja Rosdakarya, 2004), h. 195.

${ }^{14}$ Burhan Bungin, Metodologi Penelitian Sosial \& Ekonomi: Format-Format Kuantitatif dan Kualitatif untuk Studi Sosiologi, Kebijakan Publik, Komunikasi, Manajeman, dan Pemasaran Ed. 1 (Cet. I; Jakarta: Kencana, 2013), h. 48.
} 
Penelitian deskriptif sesuai karakteristiknya memiliki langkah-langkah tertentu dalam pelaksanaannya, langkah-langkah ini sebagai berikut: diawali dengan adanya masalah, menentukan jenis informasi yang diperlukan, menentukan prosedur pengumpulan data melaui obeservasi atau pengamatan, pengolahan informasi atau data, dan menarik kesimpulan penelitian

\section{HASIL DAN PEMBAHASAN}

\section{Daya Saing Produk JKN-KIS BPJS Kesehatan Cabang Bone}

Posisi daya saing produk JKN-KIS BPJS Kesehatan Cabang Bone dapat dilihat dari pencapaian jumlah cakupan kepesertannya. Data tersebut diambil dari BPJS Kesehatan Kantor Divisi Regional IX Makassar. Data tersebut telah diurut dari urutan pertama sampai urutan terakhir dengan menempatkan posisi sesuai pencapaian jumlah kepesertaan terbanyak dari lima Kantor Cabang BPJS di Sulawesi Selatan. Data tersebut yakni:

\section{Tabel 2}

Jumlah Capaian Kepesertaan Jkn-Kis Lima Kantor Cabang BPJS Kesehatan Di Sulawesi Selatan Tahun 2014-2016

\begin{tabular}{|c|l|r|l|r|r|r|}
\hline \multirow{2}{*}{ No } & \multicolumn{2}{|c|}{2014} & \multicolumn{2}{c|}{2015} & \multicolumn{2}{c|}{2016} \\
\cline { 2 - 7 } & $\begin{array}{c}\text { Kantor } \\
\text { cabang }\end{array}$ & Jumlah & $\begin{array}{c}\text { Kantor } \\
\text { cabang }\end{array}$ & Jumlah & $\begin{array}{c}\text { Kantor } \\
\text { cabang }\end{array}$ & Jumlah \\
\hline 1 & Makassar & 1.624 .051 & Makassar & 1.925 .052 & Makassar & 2.506 .361 \\
\hline 2 & Palopo & 849.053 & Watampone & 800.907 & Watampone & 1.182 .466 \\
\hline 3 & Watampone & 756.699 & Palopo & 750.081 & Palopo & 877.813 \\
\hline 4 & Pare-Pare & 540.855 & Bulukumba & 601.282 & Bulukumba & 781.414 \\
\hline 5 & Bulukumba & 530.881 & Pare-Pare & 532.924 & Pare-Pare & 715.520 \\
\hline
\end{tabular}

Sumber Data : BPJS Kesehatan Kantor Divisi Regional IX Makassar

Berdasarkan tabel di atas yang telah diolah dan diurutkan sesuai jumlah capaian kepesertaan produk JKN-KIS BPJS Kesehatan terbanyak agar dapat dlihat posisi daya saing produk JKN-KIS BPJS Kesehatan yang ada di Sulawesi Selatan. Maka dari tabel tersebut posisi tertinggi dari jumlah capaian kepesertaan produk JKN-KIS BPJS Kesehatan yakni, 
Pada tahun 2014 posisi tertinggi ditempati oleh Makassar dengan jumlah kepesertaan sebanyak 1.624.051, pada tahun 2015 posisi tertinggi ditempati oleh Makassar dengan jumlah kepesertaan sebanyak 1.925.052 dan pada tahun 2016 posisi tertinggi masih ditempati oleh Makassar dengan jumlah kepesertaan sebanyak 2.506.361 dan posisi terendah dari lima Kantor Cabang di Sulawesi Selatan tahun 2014 ditempati oleh Kantor Cabang Bulukumba dengan 530.881 peserta, pada tahun 2015 ditempati oleh Kantor Cabang Pare-Pare dengan 532.924 peserta, dan pada tahun 2016 masih ditempati oleh Kantor Cabang Pare-Pare dengan 715.520 peserta.

Berdasarkan tabel 1 di atas maka dapat didepenelitiankan peningkatan daya saing produk JKN-KIS BPJS Kesehatan Cabang Bone yakni :

posisi daya saing produk JKN-KIS BPJS Kesehatan Cabang Bone dari jumlah capaian kepesertaan di tahun 2014 berada di posisi ketiga dengan 756.699 peserta, di tahun 2015 mengalami peningkatan dari posisi ketiga ke posisi kedua dengan 800.907 peserta dan pada tahun 2016 masih berada di posisi kedua dengan 1.182.466 peserta.

\section{Peran Manajemen Sumber Daya Manusia BPJS Kesehatan Cabang Bone dalam Upaya Meningkatkan Daya Saing Produk}

1. Peran Administrasi

Peran Administrasi Manajemen Sumber Manusia BPJS Kesehatan Cabang Bone sudah didukung dengan penggunaan aplikasi Sistem Manajemen Kinerja Pegawai Berbasis Kompetensi dengan melibatkan peran teknologi dalam setiap aktivitasnya yang bersifat administratif.

Ibu Ndari Cahyaningsih menambahkan bahwa peran administrasi manajemen sumber daya manusia BPJS Kesehatan Cabang Bone memberikan sumbangsih yang sangat besar dalam mewujudkan kinerja pegawai yang handal, unggul dan terpercaya. Dengan bermodalkan hal itu maka rekrutmen peserta JKNKIS tercapai dan masyarakat umum banyak merasakan manfaat. 
"Melalui peran administrasi ini kami senantiasa melakukan penilaian kinerja terhadap pegawai yang pada akhirnya juga untuk menciptakan pegawai yang handal, unggul dan terpercaya. Yang mengarah pada maksimalnya pencapaian JKN-KIS dan masyarakat banyak merasakan manfaat." ${ }^{15}$

Jadi, peran administrasi manajemen sumber daya manusia BPJS Kesehatan Cabang Bone sudah berorientasi dan mengarah pada peningkatan kepesertaan JKN-KIS yang secara tidak langsung meningkatkan daya saing produk.

\section{Peran Operasional}

Peran operasional manajemen sumber daya manusia BPJS Kesehatan Cabang Bone lebih banyak berorientasi pada pelatihan dan pengembangan serta sistem kompetensi pegawai. Hal ini terlihat dari beberapa kegiatan diklat yang senantiasa dilakukan oleh BPJS Kesehatan yang mengarah pada peningkatan kompetensi pegawai. Seperti yang dikatakan oleh Kabid SDM, Umum dan Komunikasi Publik BPJS Kesehatan Cabang Bone, Ibu Ndari Cahyaningih sebagai berikut :

"Peran operasional kami lebih banyak ke arah bagaimana meningkatkan kompetensi pegawai, pelatihan dan pengembangan. Karena memang dalam misi perusahaan ada poin yang khusus menjadi pondasi kami dalam melaksanakan peran ini"16

Pelaksanaan peran operasional manajemen sumber daya manusia BPJS Kesehatan Cabang Bone dapat terlihat dari kegiatan Coach and Conseling yang selalu dilakukan oleh manajemen sumber daya manusia. Melalui kegiatan Coach and Conseling manajemen sumber daya manusia BPJS Kesehatan Cabang Bone berusaha untuk meningkatkan pengetahuan dan kompetensi pegawai dan

\footnotetext{
${ }^{15}$ Ndari Cahyaningsih, Kabid SDM, Umum dan Komunikasi Publik BPJS Kesehatan Cabang Bone, wawancara oleh penulis di Kantor BPJS Kesehatan Cabang Bone JI. Hos. Cokroaminoto, No. 34 Watampone, Kab. Bone, 31 Oktober 2017.

${ }^{16}$ Ndari Cahyaningsih, Kabid SDM, Umum dan Komunikasi Publik BPJS Kesehatan Cabang Bone, wawancara oleh penulis di Kantor BPJS Kesehatan Cabang Bone JI. Hos. Cokroaminoto, No. 34 Watampone, Kab. Bone, 31 Oktober 2017.
} 
membangun keterikatan pegawai dengan perusahaan sehingga pegawai bekerja lebih efektif, lebih senang dan mencintai perusahaannya.

\section{KESIMPULAN DAN SARAN}

\section{Kesimpulan}

Berdasarkan hasil analisis dan pembahasan pada sebelumnya, maka dapat ditarik kesimpulan sebagai berikut :

1. Berdasarkan dari penelitian yang dilakukan, maka dapat disimpulkan bahwa posisi daya saing produk BPJS Kesehatan Cabang Bone dari lima Kantor Cabang di Sulawesi Selatan, yang berdasarkan jumlah capaian kepesertaan yakni : BPJS kesehatan menempati posisi ketiga di tahun 2014 dengan 756.699 peserta, di tahun 2015 mengalami peningkatan dari posisi ketiga ke posisi kedua dengan 800.907 peserta dan pada tahun 2016 masih berada di posisi kedua dengan 1.182 .466 peserta.

2. Peran manajemen sumber daya manusia dalam meningkatkan daya saing produk BPJS Kesehatan Cabang Bone dapat dilihat dari tiga peran yakni :

a. Peran administrasi manajemen sumber daya manusia, BPJS Kesehatan Cabang Bone sudah menerapkan aplikasi sistem manajemen kinerja pegawai berbasis kompetensi untuk penyimpanan database dan arsip pegawai, pengumpulan dokumen dan penilaian kinerja pegawai. Sehingga senantiasa memantau kinerja pegawai yang salah satunya dalam hal perekrutan peserta JKN-KIS.

b. Peran operasional manajemen sumber daya manusia, BPJS Kesehatan Cabang Bone lebih banyak berorientasi pada pelatihan dan pengembangan serta sistem kompetensi pegawai yang terlihat dari beberapa kegiatan diklat yang senantiasa dilakukan oleh BPJS Kesehatan yang mengarah pada peningkatan kompetensi pegawai.

c. Peran strategis manajemen sumber daya manusia, BPJS Kesehatan Cabang Bone menerapkan manajemen talenta yang bertujuan untuk mendapatkan 
pegawai dengan indeks kerja tinggi demi mendapatkan sumber daya manusia yang handal, unggul, dan terpercaya.

\section{Saran}

Berdasarkan keterbatasan penelitian diatas, maka dapat disarankan hal-hal sebagai berikut:

1. Untuk BPJS Kesehatan Cabang Bone, wujud dan pelaksanaan peran manajemen sumber daya manusia sudah dapat dikatakan baik dan telah berorientasi kepada peningkatan daya saing produk. Namun, di tengah ketatnya persaingan, kita tidak boleh berpuas diri akan pencapaian yang telah diwujudkan. Kita harus senantiasa peka dengan isu-isu dari eksternal perusahaan. Dan manajemen sumber daya manusia hanya salah satu dari beberapa unsur manajemen dalam perusahaan yang harus senantiasa bersinergi dan bekerja beriringan untuk membangun daya saing yang lebih kuat.

\section{DAFTAR PUSTAKA}

A.,Usmara.ParadigmaBaruManajemenSumberDayaManusia.Yogyakarta:AmaraBooks, 2 008.

Abdullah, Thamrin dan Francis Tantri.Manajemen Pemasaran Ed. 1. Cet. II; Jakarta: Rajawali Pers, 2013.

Ardana,Komang dkk.ManajemenSumber DayaManusia.Yogyakarta:Grahallmu,2012.

Bangun,Wilson.Manajemen Sumber Daya Manusia.Jakarta: Erlangga,2012.

Bungin,Burhan.Metode Penelitian Kualitatif. Cet. I; Jakarta: PT. Raja Grafindo Persada, 2007.

Metodologi Penelitian Sosial \& Ekonomi: Format-Format Kuantitatif dan Kualitatif untuk Studi Sosiologi, Kebijakan Publik, Komunikasi, Manajeman, dan Pemasaran Ed. 1. Cet. I; Jakarta: Kencana, 2013. 
Sosiologi Komunikasi: Teori, Paradigma, dan Diskursus Teknologi Komunikasi di Masyarakat Ed. 1. Cet. Vl; Jakarta: Kencana Prenada Group, 2013.

BPJS Kesehatan, "Sejarah Perjalanan Jaminan Sosial Indonesia" dalam https://bpjskesehatan.go.id/bpjs/index.php/pages/detail/2013/4. 21 Oktober 2017.

BPJS Kesehatan "Visi dan Misi BPJS Kesehatan" dalam https://bpjskesehatan.go.id/bpjs/index.php/pages/detail/2010/2. 21 Oktober 2017.

Cravens, David W. Terjemaan Lina Salim. Pemasaran Strategis. Ed. 4. Cet. 3; Jakarta, Erlangga. 1996.

Daft,Richard L. Management (Manajemen).Jakarta: SalembaEmpat,2006.

David, Fred R. Manajemen Strategis Konsep Buku 1 Ed. 2. Jakarta: Salemba Empat, 2011.

Departemen Agama RI.Al-Qur'an Dan Tafsirnya Jilid 1. Cet, 3: Jakarta; Departemen Agama Rl, 2009. ART),2005.

Al-Qur'andanTerjemahnya.Bandung:CVJumanatul,Ali-Art(J-

Depdiknas. Kamus Bahasalndonesia.Jakarta:PusatBahasa,2008.

Dharma, Agus dkk. Keunggulan Bersaing : Menciptakan dan Mempertahankan Kinerja Unggul.Jakarta: Erlangga, 1993.

Fathoni,Abdur Rahmat.Organisasi dan Manajemen Sumber Daya Manusia. Cet. I; Jakarta: PT. Rineka Cipta, 2006.

Gomes,FaustinoCordoso.ManajemenSumberDayaManusia Ed. II. Cet. I; Yogyakarta:AndiOffset,2003.

Gumur,Alex.ManajemenKerangkaPokok-Pokok.Jakarta:Barata, 2005.

Handoko,T. Hani.Manajemen Personalia dan Sumber Daya Manusia Ed. 2. Cet. V; Yogyakarta: BPFE, 2001.

Hariandja,MarihotTuaEfendi.ManajemenSumber (Pengadaan, Pengembangan, Pengkompensasian ProduktivitasPegawai).Jakarta: PT.GramediaWidiasarana Indonesia,2002.

Harris,Michael Human Resource Management (A PracticalApproach).NewYork:Harcour Brance,1997. 